\title{
Role of curcumin in oral cancer prevention
}

\author{
Shaista Suhail ${ }^{1}$, Shalini Gupta ${ }^{1 *}$, Vijay Kumar ${ }^{2}$ and O.P. Gupta ${ }^{3}$ \\ ${ }^{1}$ Department of Oral Pathology \& Microbiology, King George's Medical University, Lucknow, UP, India \\ ${ }^{2}$ Department of Oncology, King George's Medical University, Lucknow, UP, India \\ ${ }^{3}$ Department of General Surgery, Carrier Institute of Medical Sciences and Research Center, Lucknow, UP, India
}

\begin{abstract}
Oral cancer accounts for 2-4\% of diagnosed cancers, annually in the United States. Oral cancer is a common neoplasm in Asia and the Pacific Islands, particularly in India. It is believed that oral mucosal carcinomas are predominantly caused by chemical carcinogens, although viral, fungal, and physical stimuli in the genesis of some oral neoplasms are also implicated. Curcumin, (diferuloyl methane), a hydrophobic polyphenol derived from the dietary spice turmeric, is a free radical scavenger and hydrogen donor, that exhibits both pro- and antioxidant activities. It binds metals, particularly iron and copper, and is an iron chelator. Curcumin is remarkably a non-toxic substance and exhibits limited bioavailability. In the plethora of phytochemicals derived from dietary components, natural substances traditionally used in ancient medicines for their anti-inflammatory and antioxidant actions, curcumin is studied in order to combat human diseases, especially in cancer. It has antioxidant and anti-inflammatory properties and appears able to reduce the risk of cancer. The reported activity of curcumin against leukemia and lymphoma, gastrointestinal cancers, genitourinary cancers, breast cancer, ovarian cancer, head and neck squamous cell carcinoma, lung cancer, melanoma, neurological cancers, sarcoma and oral cancer, reflects its ability to affect multiple targets in a nonlinear manner. The present review summarizes the most recent advances in the field, providing also new insights into the molecular mechanisms underlying the promising anticarcinogenic activity of the dietary polyphenol curcumin.
\end{abstract}

\section{Introduction}

Phytochemicals are naturally occurring substances found in plants. There has been considerable public and scientific interest in the use of phytochemicals derived from dietary components to combat human diseases, especially in cancer. Curcumin, a phytochemical derived from dried ground rhizome of the perennial herb Curcuma longa Linn, called turmeric in English, haldi in Hindi. Curcumin (diferuloylmethane $-\mathrm{C}_{21} \mathrm{H}_{20} \mathrm{O}_{6}$ ) is a polyphenol of low molecular weight, first chemically characterized in 1910, that comprises $2-8 \%$ of most turmeric preparations $[1,2]$. Polyphenols are the first phytochemicals that have been studied for their potential preventive and therapeutic effects. Polyphenols are derived from many components of the human diet, including dark chocolate, peanuts, green and black teas, red wine, olive oil and the spice, turmeric. Many of these natural substances, traditionally used in ancient medicines for their anti-inflammatory and antioxidant actions, are now being investigated for their cardioprotective or cancer preventive abilities [3]. It has antioxidant, anti-inflammatory and potentially chemotherapeutic properties. The purpose of the current article is to present an appraisal of the current level of knowledge regarding the potential of curcumin as an agent for the chemoprevention of oral cancer. Cancer and inflammation is a new research field that moves from basic to clinical applications where curcumin treatment has showed able to help in decreasing the incidence of oral squamous cell carcinoma (SCC).

Curcumin have pleiotropic activities derived from its complex chemistry as well as its ability to influence multiple nonlinear signaling pathways, including survival pathways such as those regulated by NFkappaB, Akt, growth factors, and cytoprotective pathways dependent on Nrf2 as well metastatic and angiogenic pathways. Curcumin is a free radical scavenger and hydrogen donor, and exhibits both pro- and antioxidant activity. It also binds metals, particularly iron and copper, and can function as an iron chelator. Curcumin is remarkably non- toxic chemical and exhibits limited bioavailability [4]. A low level of physiologically achievable concentrations of curcumin is sufficient for its chemotherapeutic and chemopreventive activity. Curcumin also regulates multiple targets (multitargeted therapy), which is needed for the treatment of most diseases, it is inexpensive and has been found to be safe in human clinical trials.

Oral cancer accounts for $2-4 \%$ of the cancers diagnosed annually in the United States. It is a common neoplasm in Asia and the Pacific Islands, particularly in India. Oral mucosal carcinomas are predominantly caused by chemical carcinogens, although viral, fungal, and physical stimuli in the genesis of some oral neoplasms are also implicated [5]. Tobacco and alcohol are the major causative agents of oral carcinoma [6].

Chemoprevention of oral cancer have been preliminarly conducted by using hamster buccal pouch and use of beta-carotene for chemoprevention [7]. Beta-carotene, a versatile antioxidant, contains the highest potential of vitamin A activity, has a preventive effect not only on hamster buccal pouch carcinogenesis but can also retard the progressive changes of premalignant lesions in the oral cavity of humans $[8,9]$.

\section{Inhibition of cyclooxygenase transcription}

Curcumin have anti-inflammatory and antioxidant activities

Correspondence to: Dr. Shalini Gupta, Department of Oral Pathology and Microbiology, King George's Medical University, Lucknow, UP, India, E-mail: sgmds2002@yahoo.co.in

Key words: curcumin, oral cancer, cancer prevention

Received: October 21, 2015; Accepted: November 17, 2015; Published: November 21, 2015 
which results in the inhibition of lipo-oxygenase and cyclo-oxygenase activities that can induce inflammation.

For over a decade it has been known that curcumin have the ability to inhibit cyclooxygenase (COX) enzyme activity in human platelets [10]. COX a key enzyme is responsible in conversion of arachidonic acid to prostaglandins and thromboxanes. It consists of two different isoforms, designated COX-1 and COX-2. COX-1, it is a constitutive isoform present in most tissues and it is generally regarded as an housekeeping enzyme; its inhibition results in serious effects such as peptic ulceration or impairment of renal blood flow, while COX-2 is constitutively expressed only in brain and spinal cord tissue; it can be induced in a wide variety of normal tissues by cytokines, growth factors, oncogenes and tumour promoters [11]. COX-2 is overexpressed in the carcinogenesis of head and neck tumours [12]. Curcumin inhibits induction of COX-2 gene expression in oral and colon epithelial cells $[13,14]$. The inhibitors of COX-2, which inhibits the catalytic activity of the COX enzyme, such as curcumin, decrease the expression of COX-2 at transcriptional level [15]. The gene inhibition of COX-2 is probably the main anti-inflammatory activity of curcumin.

Curcumin has the ability to inhibit activation of pathways that interact with the NF-jB pathway, notably those involving activator protein-1 (AP-1) and c-Jun NH2-terminal kinases (JNK) [16,17]. The AP-1 and JNK pathways constitute a group of terminal kinases which are involved in cellular responses to environmental stress, proinflammatory cytokines, mitogen stimulation and apoptotic stimuli. Curcumin demonstrates an inhibitory effects on Cox-2 and cyclin D1, mediated through NF-jB, and restricts tumor cell growth.

\section{Inhibition of carcinogenesis after application of curcumin}

Application of curcumin thrice weekly to the buccal pouch of Syrian golden hamsters causes inhibition of DMBA-induced oral carcinogenesis [18].

Antioxidant actions: ROS (Reactive oxygen species), acts as a major "catalyst" in tumor promotion and progression stages through complex nonlinear pathways [19].

ROS(Reactive oxygen species), such as superoxide anions and hydroxyl radicals play a pivotal role in carcinogenesis as curcumin has the ability to scavenge superoxide anion radicals and hydroxyl radicals [20] and possess pro-oxidant activity, antioxidant effects, dependent on dose and chemical environment i.e. presence of certain chemicals [21].

ROS damage proteins, DNA and RNA, and oxidizes cell membrane fatty acids increasing mutation risk. ROS also play important roles in a variety of normal processes and considered as endogenous mitogenic factors that may also activate NF-kB and other transcription factors into the nucleus.

Enzyme NO synthases (NOS) synthesizes Nitric oxide (NO) from L-arginine by various NADPH-dependent enzymes. NO also plays a physiological role as oxidant, inflammatory, immune-modulator substance and it is also active in vasorelaxation, neurotransmission, inhibition of platelet aggregation, immune defence and intracellular signalling [22]. NO is a free radical species and its bioactivity results in production of many reactive intermediates, many of which cause DNA damage or hinder DNA repair mechanisms [23,24].

Resistance to NO-induced apoptosis in malignant cells occurs, due to increasing intracellular concentrations of reduced glutathione, or upregulation of COX-2 via NF-jB or AP-1 pathways $[25,26]$.

Effects on cell cycle: The anticarcinogenic effects of curcumin causes perturbations in cell cycle progression. The main features of cell cycle progression is the synthesis of DNA (S phase) and separation of two daughter cells ( $M$ phase). G2 phase is the time gap between the $\mathrm{S}$ and $\mathrm{M}$ phases. This phase is important, it allows the cells to repair errors that occur during DNA duplication, preventing the propagation of these errors to daughter cells while the G1 phase represents the period of commitment to cell cycle progression that separates $M$ and $\mathrm{S}$ phases as cells prepare for DNA duplication upon mitogenic signals. Curcumin inhibits the proliferation of cell, induces apoptosis and causes accumulation of cells in the G2/M phase of the cell cycle [27]. Curcumin also affects the cell-cell adhesion proteins, like b-catenin and E-cadherin, and inhibits the production of cytokines relevant to tumour growth, decreasing the expression of membrane surface molecules that play a role in cellular adhesion, through complex nonlinear pathways.

Anti-inflammatory effects: Curcumin also suppresses the inflammatory response which inhibits the induction of COX-2, iNOS and production of cytokines such as interferon-c, due to the suppression of Janus kinase (JAK) -STAT nonlinear signalling cascade [26]. Curcumin also inhibits the phosphorylation of STAT3 and suppresses interleukin-6 production [28].

\section{Anticancer effects}

Curcumin expresses anti-oxidant, anti-inflammatory, antiantigenic, anti-mitotic and anti-metastatic activities in animal. In effect, Curcumin appears to be a promising molecule for the prevention and treatment of cancer in humans. For example, curcumin induces apoptosis of cancer cells by a variety of mechanisms and inhibits the DNA topoisomerase II [29]. In the Familial adenomatous polyposis (FAP), an autosomal dominant condition characterized by the development of numerous bowel adenomas that can transform to adenocarcinoma, Curcumin shows activity against preneoplastic lesions [30]. Curcumin also down-regulates the expression of NF- $\kappa \mathrm{B}$, COX-2, TNF and activates host macrophages as well natural killer cells [31].

\section{Conclusion}

Cancer is one of life threatening disease of the world. The use of herbs is the cheapest method to cure the disease or to prevent it.

This review summarized recent developments in cancer treatment methods with the herb curcumin, a free radical scavenger and hydrogen donor that exhibits both pro- and antioxidant activities. It binds metals, particularly iron and copper, and can function as an iron chelator. Curcumin is a non-toxic natural substance, effective in treatment or prevention of cancer, e.g. of oral precancerous stages.

\section{References}

1. Heath DD, Khwaja F, Rock CL (2004) Curcumin content of turmeric and curry powders. FASEB J 18: A125.

2. Strimpakos AS, Sharma RA (2008) Curcumin: preventive and therapeutic properties in laboratory studies and clinical trials. Antioxid Redox Signal 10: 511-545. [Crossref]

3. Hatcher H, Planalp R, Cho J, Torti FM, Torti SV (2008) Curcumin: from ancient medicine to current clinical trials. Cell Mol Life Sci 65: 1631-1652. [Crossref]

4. Smith CJ (1989) Oral cancer and precancer: background, epidemiology and aetiology. Br Dent J 167: 377-383. [Crossref] 
5. Sankaranarayanan R (1990) Oral cancer in India: an epidemiologic and clinical review. Oral Surg Oral Med Oral Pathol 69: 325-330. [Crossref]

6. Wattenberg LW, Lipkin M, Boone CW, Kelloff GJ (Eds.) (1992) Chemoprevention of cancer by naturally occurring and synthetic compounds. Cancer Chemoprevention 19-39. Boca Raton, FL: CRC Press.

7. Garewal HS (1993) Carotenoids in oral cancer prevention. Ann N Y Acad Sci 691: 139-147. [Crossref]

8. Shklar G, Schwartz J (1993) Oral cancer inhibition by micronutrients. The experimental basis for clinical trials. Eur J Cancer B Oral Oncol 29B: 9-16. [Crossref]

9. Ammon HP, Wahl MA (1991) Pharmacology of Curcuma longa. Planta Med 57: 1-7. [Crossref]

10. Taketo MM (1998) Cyclooxygenase-2 inhibitors in tumorigenesis (Part II). $J$ Nat Cancer Inst 90: 1609-1620. [Crossref]

11. Sharma RA (2002) Translational medicine: targetting cyclo-oxygenase isozymes to prevent cancer. QJM 95: 267-273. [Crossref]

12. Khafif A, Schantz SP, Chou TC, Edelstein D, Sacks PG (1998) Quantitation of chemopreventive synergism between (-)-epigallocatechin-3-gallate and curcumin in normal, premalignant and malignant human oral epithelial cells. Carcinogenesis 19 419-424. [Crossref]

13. Zhang F, Altorki NK, Mestre JR, Subbaramaiah K, Dannenberg AJ (1999) Curcumin inhibits cyclooxygenase- 2 transcription in bile acid- and phorbol ester-treated human gastrointestinal epithelial cells. Carcinogenesis 20: 445-451. [Crossref]

14. Plummer SM, Holloway KA, Manson MM, Munks RJ, Kaptein A, et al. (1999) Inhibition of cyclo-oxygenase 2 expression in colon cells by the chemopreventive agen curcumin involves inhibition of NF-kappaB activation via the NIK/IKK signalling complex. Oncogene 18: 6013-6020. [Crossref]

15. Huang TS, Lee SC, Lin JK (1991) Suppression of c-Jun/AP-1 activation by an inhibitor of tumor promotion in mouse fibroblast cells. Proc Natl Acad Sci U S A 88: 5292-5296. [Crossref]

16. Chen YR, Tan TH (1998) Inhibition of the c-Jun N-terminal kinase (JNK) signaling pathway by curcumin. Oncogene 17: 173-178. [Crossref]

17. Li N, Chen X, Liao J, Yang G, Wang S, et al. (2002) Inhibition of 7,12-dimethylbenz[a] anthracene (DMBA)-induced oral carcinogenesis in hamsters by tea and curcumin. Carcinogenesis 23: 1307-1313. [Crossref]

18. Kunchandy E, Rao MNA (1990) Oxygen radical scavenging activity of curcumin. Int $J$ Pharmaceut 58: 237-240
19. Reddy AC, Lokesh BR (1994) Studies on anti-inflammatory activity of spice principles and dietary n-3 polyunsaturated fatty acids on carrageenan-induced inflammation in rats. Ann Nutr Metab 38: 349-358. [Crossref]

20. Ahsan H, Parveen N, Khan NU, Hadi SM (1999) Pro-oxidant, anti-oxidant and cleavage activities on DNA of curcumin and its derivatives demethoxycurcumin and bisdemethoxycurcumin. Chem Biol Interact 121: 161-175. [Crossref]

21. Lala PK, Chakraborty C (2001) Role of nitric oxide in carcinogenesis and tumour progression. Lancet Oncol 2: 149-156. [Crossref]

22. deRojas-Walker T, Tamir S, Ji H, Wishnok JS, Tannenbaum SR (1995) Nitric oxide induces oxidative damage in addition to deamination in macrophage DNA. Chem Res Toxicol 8: 473-477. [Crossref]

23. Graziewicz M, Wink DA, Laval F (1996) Nitric oxide inhibits DNA ligase activity: potential mechanisms for NO-mediated DNA damage. Carcinogenesis 17: 2501-2505. [Crossref]

24. von Knethen A, Brüne B (1997) Cyclooxygenase-2: an essential regulator of NOmediated apoptosis. FASEB J 11: 887-895. [Crossref]

25. Kim HY, Park EJ, Joe EH, Jou I (2003) Curcumin suppresses janus kinase-STAT inflammatory signaling through activation of Src homology 2 domain-containing tyrosine phosphatase 2 in brain microglia. J Immunol 171: 6072-6079. [Crossref]

26. Bharti AC, Donato N, Aggarwal BB (2003) Curcumin (diferuloylmethane) inhibit constitutive and IL-6 inducible STAT3 phosphorylation in human multiple myeloma cells. J Immunol 171: 3863-3871. [Crossref]

27. Martín-Cordero C, López-Lázaro M, Gálvez M, Ayuso MJ (2003) Curcumin as a DNA topoisomerase II poison. J Enzyme Inhib Med Chem 18: 505-509. [Crossref]

28. Cruz-Correa M, Shoskes DA, Sanchez P, Zhao R, Hylind LM, et al. (2006) Combination treatment with curcumin and quercetin of adenomas in familial adenomatous polyposis. Clin Gastroenterol Hepatol 4: 1035-1038. [Crossref]

29. Hanif R, Qiao L, Shiff SJ, Rigas B (1997) Curcumin, a natural plant phenolic food additive, inhibits cell proliferation and induces cell cycle changes in colon adenocarcinoma cell lines by a prostaglandin-independent pathway. J Lab Clin Med 130: 576-584. [Crossref]

30. Bhaumik S, Jyothi MD, Khar A (2000) Differential modulation of nitric oxide production by curcumin in host macrophages and NK cells. FEBS Lett 483: 78-82. [Crossref]

31. Chan MM (1995) Inhibition of tumor necrosis factor by curcumin, a phytochemical. Biochem Pharmacol 49: 1551-1556. [Crossref]

Copyright: (C2015 Suhail S. This is an open-access article distributed under the terms of the Creative Commons Attribution License, which permits unrestricted use, distribution, and reproduction in any medium, provided the original author and source are credited. 